\title{
Downscaling of Seasonal Rainfall over the Philippines: Dynamical versus Statistical Approaches
}

\author{
Andrew W. Robertson, Jian-Hua Qian,* And Michael K. TippetT \\ International Research Institute for Climate and Society, Earth Institute, Columbia University, Palisades, New York
}

VINCENT MORON

Aix-Marseille University, and CEREGE, Aix-en-Provence, France, and International Research Institute for Climate and Society, Earth Institute, Columbia University, Palisades, New York

ANTHONY LUCERO

Philippine Atmospheric Geophysical and Astronomical Services Administration, Manila, Philippines

(Manuscript received 19 July 2011, in final form 1 November 2011)

\begin{abstract}
The additional value derived from a regional climate model (RCM) nested within general circulation model (GCM) seasonal simulations, over and above statistical methods of downscaling, is compared over the Philippines for the April-June monsoon transition season. Spatial interpolation of RCM and GCM gridbox values to station locations is compared with model output statistics (MOS) correction. The anomaly correlation coefficient (ACC) skill at the station scale of seasonal total rainfall is somewhat higher in the RCM compared to the GCM when using spatial interpolation. However, the ACC skills obtained using MOS of the GCM or RCM wind fields are shown to be generally—and rather equally—superior. The ranked probability skill scores (RPSS) are also generally much higher when using MOS, with slightly higher scores in the GCM case. Very high skills were found for MOS correction of daily rainfall frequency as a function of GCM and RCM seasonal-average low-level wind fields, but with no apparent advantage from the RCM. MOS-corrected monsoon onset dates often showed skill values similar to those of seasonal rainfall total, with good skill over the central Philippines. Finally, it is shown that the MOS skills decrease markedly and become inferior to those of spatial interpolation when the length of the 28-yr training set is halved. The results may be region dependent, and the excellent station data coverage and strong impact of ENSO on the Philippines may be factors contributing to the good MOS performance when using the full-length dataset over the Philippines.
\end{abstract}

\section{Introduction}

In order for general circulation model (GCM) climate forecasts to be of practical societal value, it has long been recognized that it is essential for them to be issued at spatial scales appropriate to the decision maker or at the scale needed to exploit them further, such as using hydrologic or crop simulation models. Because the GCMs

\footnotetext{
* Current affiliation: Department of Environmental, Earth and Atmospheric Sciences, University of Massachusetts-Lowell, Lowell, Massachusetts.

Corresponding author address: Andrew W. Robertson, IRI, Lamont Campus, 61 Route 9W, Palisades, NY 10964.

E-mail: awr@iri.columbia.edu
}

used for seasonal forecasting are often run at coarse spatial resolutions of say $300 \mathrm{~km}$ (Goddard et al. 2003), some type of "downscaling" is usually performed using either statistical methods or a nested high-resolution regional climate model (RCM). The latter method is often called "dynamical downscaling" (e.g., Sun et al. 2005) to distinguish it from the statistical variety, although some statistical calibration of the RCM output may still be required. Dynamical downscaling requires ensembles of high-resolution limited area simulations, which are much more labor and computationally intensive than statistical methods; it also generally requires 6-hourly full three-dimensional fields from the GCM to be archived, which is highly storage intensive and often not done routinely. On the other hand, statistical methods require sufficiently long records of observed high-resolution data 

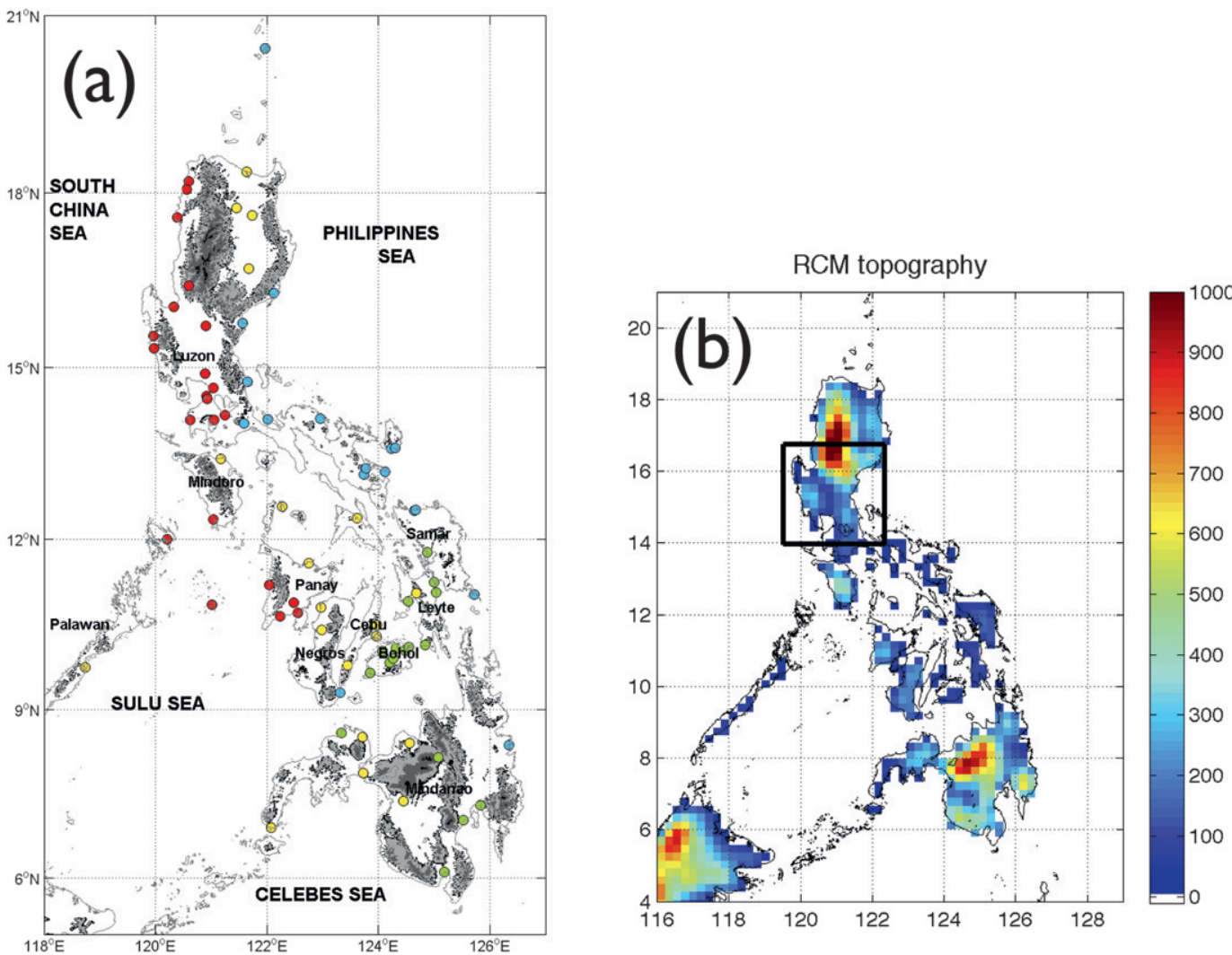

FIG. 1. (a) Location of the 76 stations with shadings representing altitudes 500-1000 m (light gray), 1000-2000 m (medium gray), and $>2000 \mathrm{~m}$ (black). The colors refer to the modified Coronas climate classification of the Philippines types I (red), II (blue), III (yellow), and IV (green). (b) RegCM3 25-km orography (m). The box indicates the single GCM land grid point.

in order to both train and validate them, which may be unavailable in data-poor regions. Statistical methods may also run into difficulties when applied to climate change projections because of stationarity assumptions (Fowler et al. 2007).

The goal of this paper is to compare statistical and dynamical downscaling methods over the Philippines for the April-June (AMJ) monsoon transition season, using a high-quality 28 -yr, 77 -station daily rainfall dataset. The Philippines is a region of complex island topography that is very poorly (if at all; see Fig. 1b) represented by coarse GCM seasonal forecast models. This, together with the availability of high-quality station data, makes the Philippines an ideal test bed for the intercomparison of methods. On the seasonal time scale, the Philippines is strongly impacted by the El Niño-Southern Oscillation (ENSO), with El Niño events tending to be associated with below-normal rainfall, except during July-September, when the signal reverses (Lyon et al. 2006). The onset of the summer monsoon in rainfall takes place during AprilJune and has been shown to be strongly modulated by ENSO, with delayed onset in El Niño years and vice versa
(Moron et al. 2009). Local rainfall is affected by mountains and coastlines through physical processes of mechanical lifting of moist air on the windward side (more rainfall) and the rain shadow on the leeward side, as well as thermodynamical forcing of mountain-valley and landsea breezes. The Philippines contains many mountainous islands and a sufficiently high-resolution representation of mountains and coastlines is expected to be important in order to capture these finescale forcings of mountains and land-sea contrasts.

Statistical downscaling methods range from simple spatial interpolation and corrections of local bias in the mean and standard deviation (e.g., Wilby et al. 1998; Widmann et al. 2003) to regression methods based on model output and observed data that can also remove conditional biases, often referred to as model output statistics (MOS) correction. Multiple linear regression models can be prone to artificial skill through statistical overfitting, but robust cross-validated multivariate methods based on principal components (PCs) regression and canonical correlation analysis (CCA) have been developed to overcome these difficulties (e.g., Tippett et al. 2003; Verbist et al. 2010). 
(a) CMORPH/NNRP

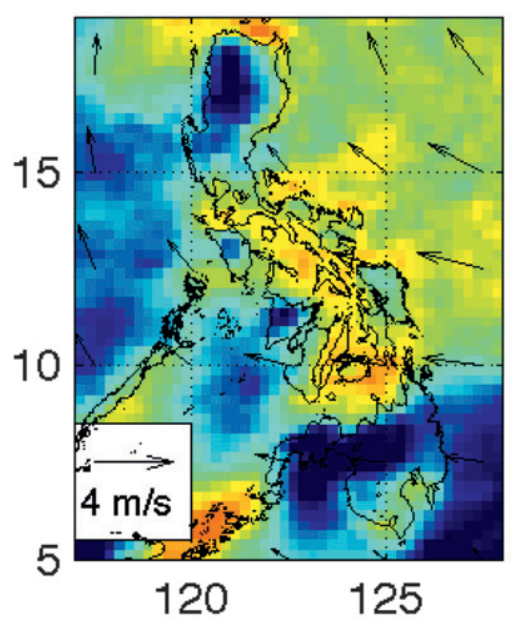

(c) GCM

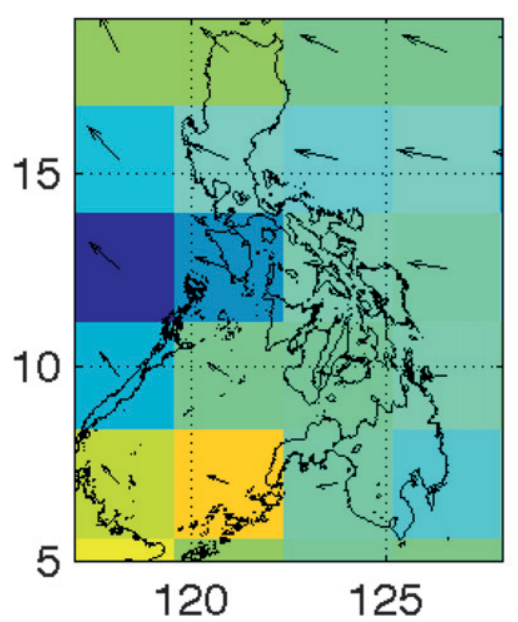

(b) PAGASA
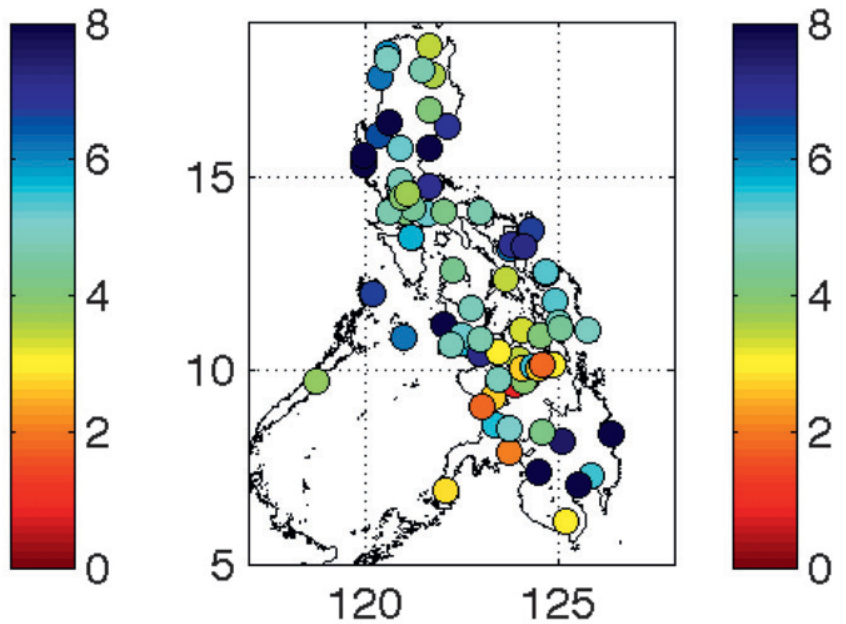

(d) RCM

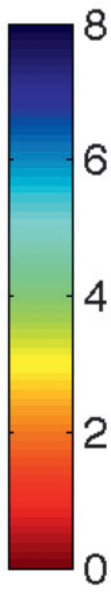

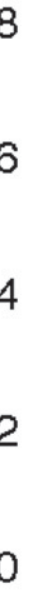

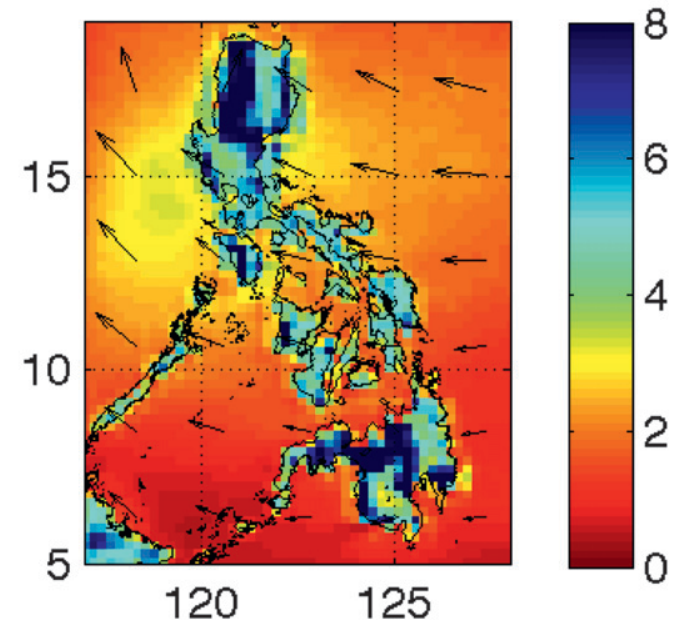

FIG. 2. April-June mean rainfall and 850-hPa wind climatologies from (a) CMORPH (2005-10) and 850-hPa reanalysis winds, (b) PAGASA stations, (c) GCM, and (d) RCM. All fields are for the 1977-2004 period, except for the CMORPH. Rainfall units are $\mathrm{mm} \mathrm{day}^{-1}$. Wind vectors are plotted every 10 th RCM grid point in (d).

The impact of seasonal climate anomalies on society, such as through their effect on crop growth, is often felt through changes in daily weather characteristics, such as the frequency and length of dry spells or changes in the onset date of the rainy season (e.g., Hansen et al. 2006), rather than changes in seasonal rainfall totals. Regional climate models have been shown to be skillful at capturing anomalies in daily weather statistics (Sun et al. 2007), whereas statistical downscaling methods have also claimed success, such as hidden Markov models (HMMs) that generate stochastic daily sequences of rainfall conditioned on GCM seasonal forecasts (Robertson et al. 2009) or that reproduce daily statistics directly, such as rainfall frequency (Verbist et al. 2010).

The focus of this paper is on the abilities of dynamical and statistical downscaling methods to skillfully simulate interannual anomalies of the seasonal total of precipitation, the frequency of rainy days above different thresholds, and the monsoon onset date for the April-June season. The primary comparison will be between (i) the GCM and RCM simulations of precipitation interpolated linearly to the station locations and (ii) MOS corrections of station values using CCA applied to the GCM and RCM output, together with the station rainfall data (section 2a). The ensemble of GCM simulations is 
(a) PAGASA

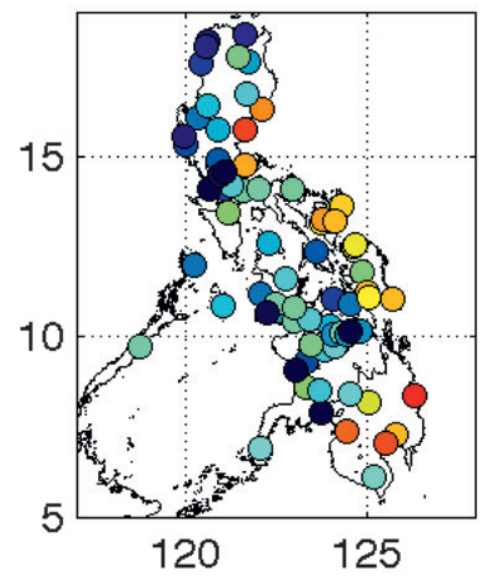

(c) RCM-land

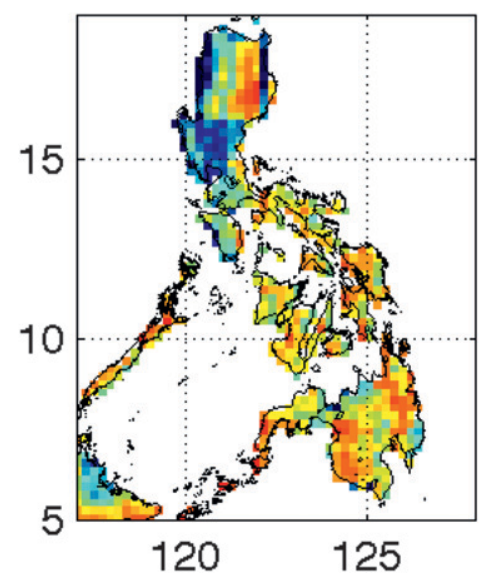

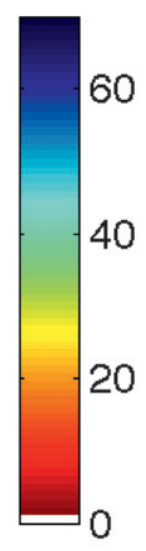

40

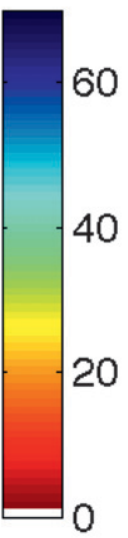

(b) GCM

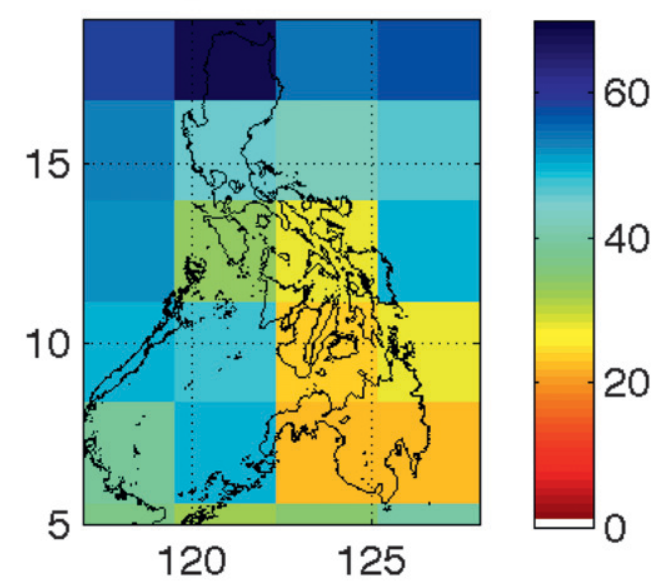

(d) RCM-station locations

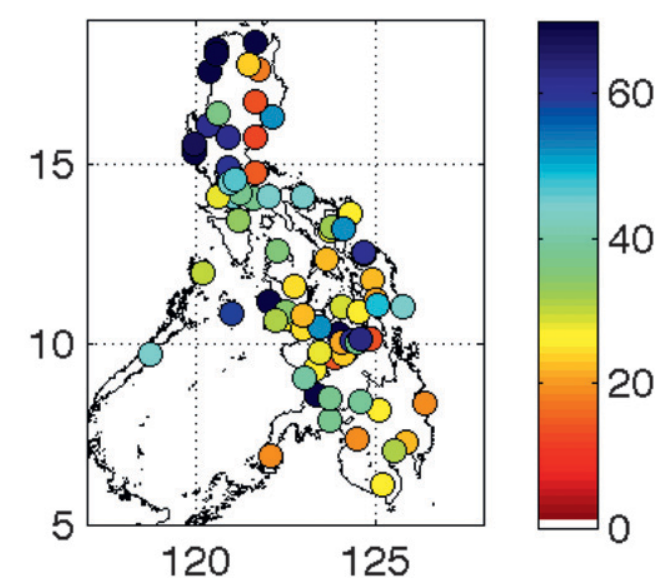

FIG. 3. Climatological-mean monsoon onset date calculated at (a) PAGASA stations, (b) GCM grid points, (c) RCM land points, and (d) RCM points closest to station locations. Units are days from 1 Apr.

driven with observed estimates of sea surface temperatures (SSTs) (section 2c), within which the RCM is nested (section $2 \mathrm{~d}$ ). The results are presented in section 3, with a summary and conclusions given in section 4 .

\section{Models and data}

\section{a. Station rainfall data}

The analysis of station rainfall is based on a 77-station network of daily rainfall records from 1977-2004 compiled and quality controlled by the Philippine Atmospheric Geophysical and Astronomical Services Administration (PAGASA). Daily rainfall amounts of less than $1 \mathrm{~mm}$ were set to zero before the analysis to reduce possible biases associated with very small rainfall amounts
(Moron et al. 2009). Missing entries ( $<3 \%$ ) are typically scattered in space and time, although one station (San José, Mindoro) had four contiguous missing years (197780). The missing data were filled as in Moron et al. (2009) using a simple stochastic weather generator (SWG) applied at each station individually, with parameters estimated separately for each calendar month (Wilks and Wilby 1999). The sequence of dry and wet days is simulated using the Markov chain principle, with the dryto-dry and wet-to-dry persistence computed from the available data. Rainfall amounts of wet days $>1 \mathrm{~mm}$ are sampled stochastically from a gamma distribution with shape and scale parameters computed from the available wet days.

The station locations are shown in Fig. 1a and are color coded according to the four Philippines climate 


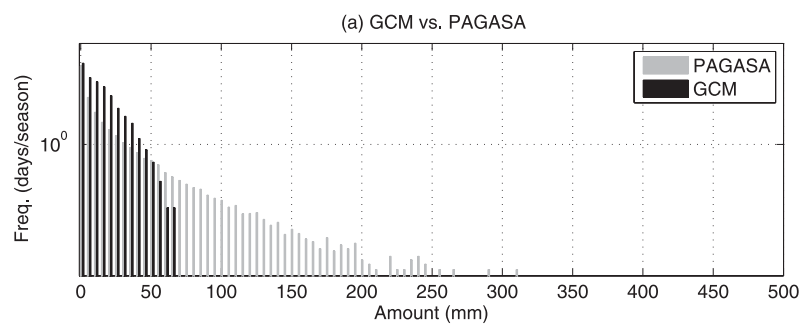

(b) RCM vs. PAGASA

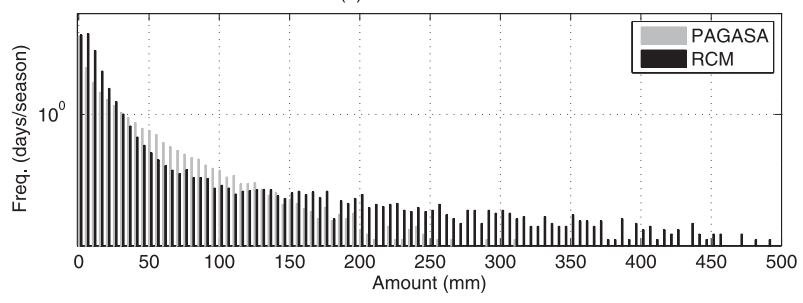

FIG. 4. Histograms of daily precipitation over (a) single GCM land point vs PAGASA stations and (b) RCM vs PAGASA using closest RCM grid points to the PAGASA station locations. Mean rainfall intensities on wet days $(\geq 1 \mathrm{~mm})$ are $15.8,6.8$, and $8.5 \mathrm{~mm} \mathrm{day}^{-1}$ for PAGASA, RCM, and GCM respectively, whereas these values are $50.0,81.5$, and $34.1 \mathrm{~mm} \mathrm{day}^{-1}$ for heavy rainfall days $\left(>25 \mathrm{~mm} \mathrm{day}^{-1}\right)$.

types employed by PAGASA, based on the classification by Coronas (1920). Red dots represent type-I climate (two pronounced seasons with a dry period from November to April and a wet period from May to October); blue dots represent type-II climate (no dry season with a very pronounced maximum rainfall during the months of November and December); yellow dots represent type-III climate (seasons not very pronounced with a relatively dry period from November to April, as in type I); and green dots represents type-IV climate, with rainfall more or less evenly distributed throughout the year.

\section{b. Gridded datasets}

The National Centers for Environmental Prediction (NCEP) Climate Prediction Center (CPC) morphing technique $(\mathrm{CMORPH})$ uses precipitation estimates from low-orbit satellite microwave observations, with features that are evolved between observations via spatial propagation information obtained from geostationary infrared satellite data (Joyce et al. 2004). We used the version at $0.25^{\circ}$ resolution from 7 December 2002 to 31 May 2007. This dataset is used as reference climatology for the RCM simulations, which have similar horizontal resolution (see below). The daily NCEP-National Center for Atmospheric Research (NCAR) reanalysis (Kalnay et al. 1996) on a $2.5^{\circ}$ grid is used as an estimate of observed winds.

\section{c. $G C M$}

The GCM is the ECHAM4.5 atmospheric general circulation model (Roeckner et al. 1996), run at T42 resolution-which corresponds to a grid resolution of approximately $2.8^{\circ}$, or about $300 \mathrm{~km}$-for which an ensemble of 10 integrations is selected randomly from the 24-member ensemble made at the International Research Institute for Climate and Society (IRI) with historical monthly SSTs prescribed at the lower boundary from the NCEP-NCAR reanalysis dataset. Each ensemble member uses the identical version of the GCM and differs only in its initial condition. The Philippines is represented by a single land grid point (over Luzon) in this GCM (Fig. 1b). The ECHAM4.5 datasets are available via the IRI/Lamont-Doherty Earth Observatory (LDEO) climate data library (http://iridl.ldeo. columbia.edu).

\section{d. $R C M$}

A set of regional model simulations was made over the Philippines with a $25-\mathrm{km}$ grid resolution, in order to resolve the forcing by local mountains and coastlines, using the Abdus Salam International Centre for Theoretical Physics (ICTP) Regional Climate Model version 3 (RegCM3) (Pal et al. 2007; Qian 2008). Its dynamical core is close to that of the hydrostatic version of the fifth-generation Pennsylvania State UniversityNCAR Mesoscale Model (MM5), a gridpoint mesoscale model based on the primitive atmospheric equations. Cumulus convection is parameterized using the EmanuelMassachusetts Institute of Technology (MIT) scheme (Emanuel and Zivkovic-Rothman 1999). The vertical resolution is based on a pressure-based terrain-following sigma coordinate. There are 18 vertical levels with 6 levels in the lower atmosphere below $1.5-\mathrm{km}$ height. The model was driven with historical SST within the model domain (approximately $4^{\circ}-21^{\circ} \mathrm{N}, 116^{\circ}-129^{\circ} \mathrm{E}$ ) and at the lateral boundaries using 6-hourly three-dimensional fields from the GCM. Further details of the RegCM3 implementation are the same as those described in Qian (2008).

The terrain and domain of the RegCM3 are shown in Fig. 1b. The model roughly resolves the mountains over northwestern Luzon in the north and northern Mindanao in the south, but many of the details are missing compared to digital elevation map in Fig. 1a. The maximum model elevation is at $1147 \mathrm{~m}$ over Luzon, considerably underestimating the actual mountain (volcano) heights, which reach up to $2954 \mathrm{~m}$ (Mount Apo) in Mindanao and 2922 m (Mount Pulag) in Luzon. The complex Philippines coastline is fairly well approximated by the RCM (especially or large islands such as Luzon in the north and 
(a) r(GCM, Obs)

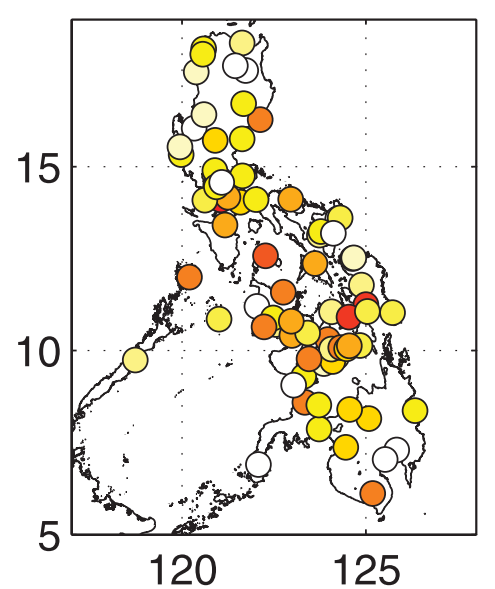

(b) $r(\mathrm{RCM}, \mathrm{Obs})$

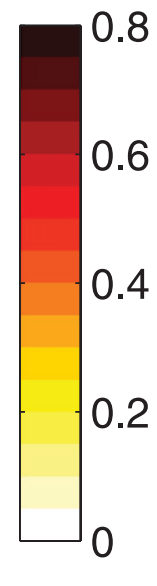

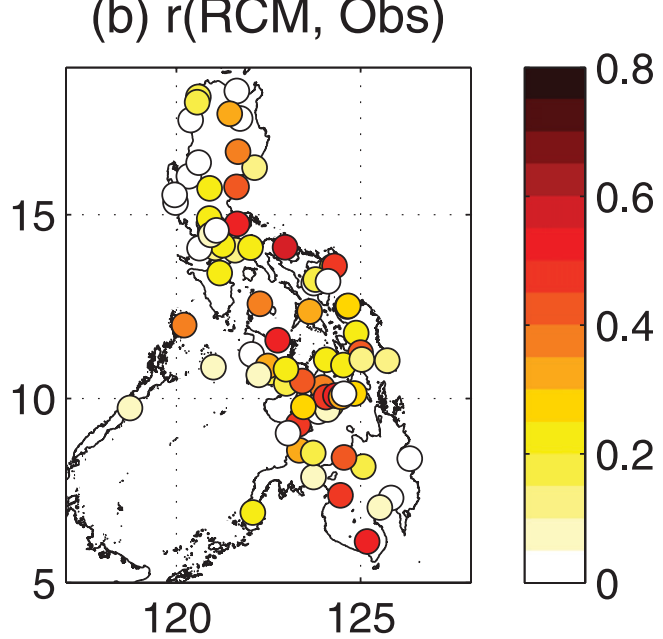

(c) Correlation values

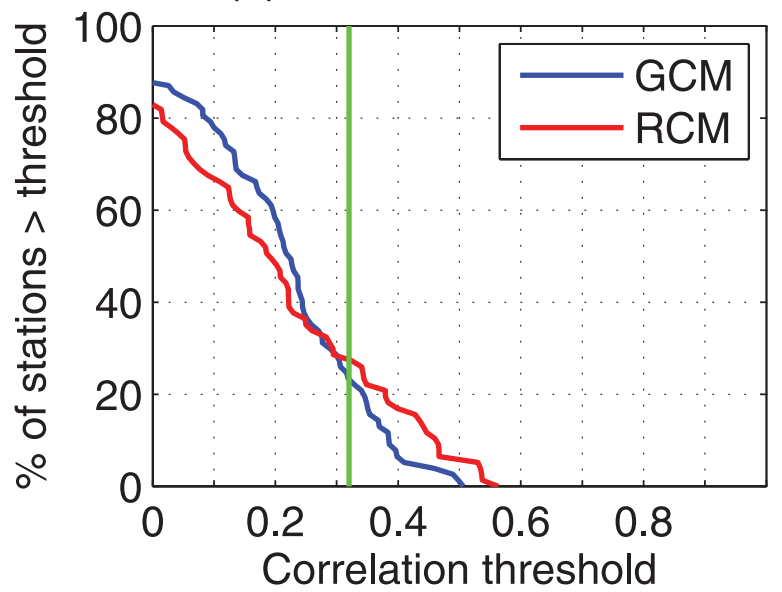

FIG. 5. ACC between AMJ seasonal-average PAGASA rainfall data and (a) GCM- and (b) RCM-simulated precipitation interpolated to station locations. (c) The percentage of stations exceeding a given correlation value, with the $95 \%$ one-tailed statistical significance value indicated as vertical line. Only positive values are plotted.

Mindanao in the south), although many of the small islands (especially those in the central Philippines) are missed. Despite its deficiencies, the RCM provides a dramatically more realistic representation of the Philippines compared to the GCM, which represents it by a single land point.

Ten RegCM3 simulations were made, driven by at the lateral boundaries by the 10 members of the ECHAM4.5 GCM, over the period 1971-2007, from which the 19772004 seasons were selected to match the availability of the PAGASA station data, over the April-June season of interest. The RegCM3 datasets are publicly available via the IRI/LDEO climate data library (http://iridl.ldeo. columbia.edu/SOURCES/.IRI/.MP/.RESEARCH/. ATMOSPHERE/.REGIONAL/.RegCM3/.SEAsia/. phil/.ECHAM/.HINDCAST/).

\section{e. Definition of monsoon onset date}

An agronomic definition of monsoon onset date is used, based on local rainfall thresholds. The monsoon onset date is defined to be the first wet day of the first 5-day wet spell receiving at least the April-September climatological mean wet-spell amount, without a 15-day dry spell receiving less than $5 \mathrm{~mm}$ in the 30 days following the start of that period. The second criterion helps to avoid onset dates that represent "false starts." The computation begins on 1 April, which is the driest month of the year climatologically (averaged across all locations). This approach follows Moron et al. (2009), whereas the use of a climatological mean wet-spell amount in place of a fixed threshold adjusts for biases in model rainfall (Moron et al. 2010). Although the 75th percentile of the PAGASA 
(a) RPSS(GCM)

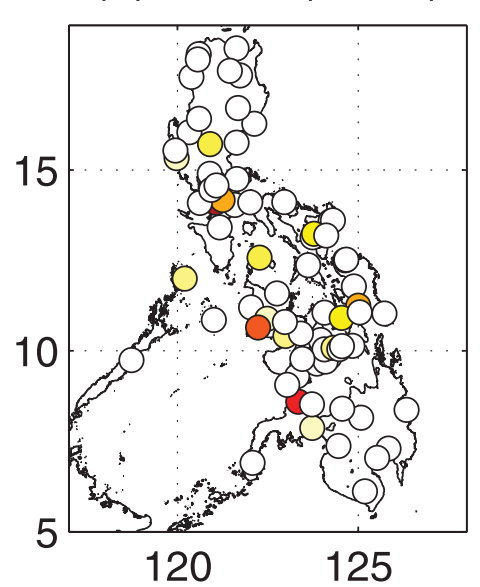

(b) RPSS(RCM)

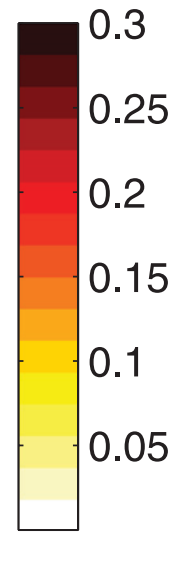

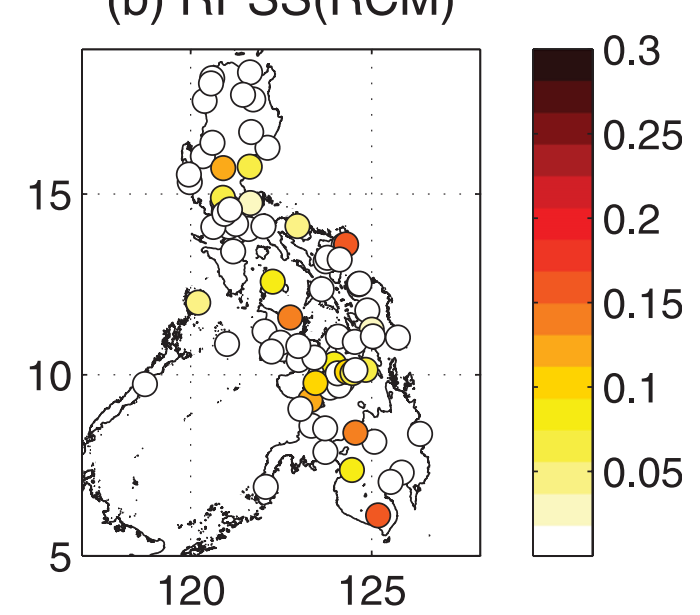

(c) RPSS values

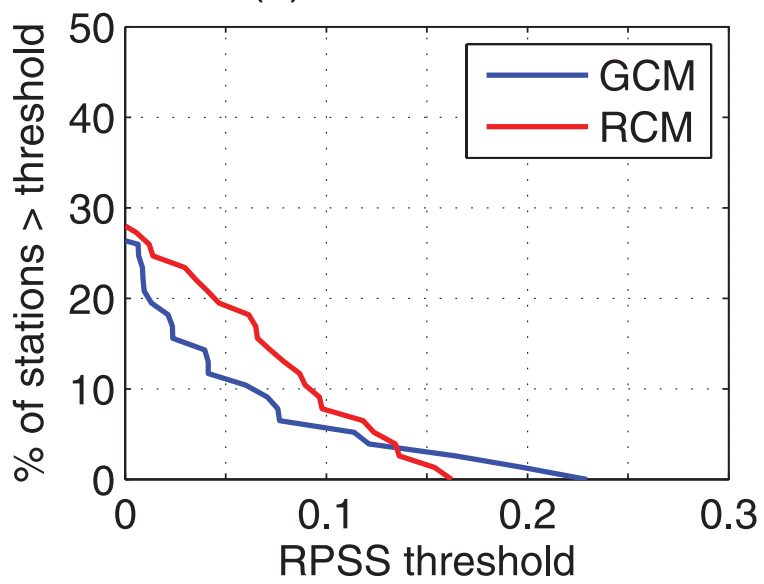

FIG. 6. RPSS for simulations of AMJ seasonal-average rainfall interpolated to station locations: (a) GCM, (b) RCM, and (c) histograms of RPSS values. Only positive RPSS values are plotted.

station onset distribution falls within May for all four climate types (see Table 5 of Moron et al. 2009), it was found to be necessary to use the April-September period in the onset calculation, in order to avoid numerous undefined onset dates.

\section{Results}

\section{a. Climatological averages}

Maps of long-term-average precipitation and low-level winds for the April-June season are shown in Fig. 2 from the various datasets. Station rainfalls are largest toward the north and south (Fig. 2b). This is reproduced to some extent by the CMORPH dataset (Fig. 2a), as well as by the RCM (Fig. 2d), whereas the GCM-not surprisingly-fails to reproduce these regional variations of rainfall. The orographic rainfall amplification over Luzon and Mindanao seen in the CMORPH is captured by the RCM, despite the underestimated topographic heights, but the land-sea rainfall contrast is much larger in the RCM as compared to the CMORPH. This characteristic of the regional model is also seen over Indonesia, and it is likely that the convective scheme underestimates the strength of deep convection over oceans and/or overestimates it over topography (Qian 2008; Moron et al. 2010). The low-level southeasterly winds associated with the subtropical anticyclone over the Pacific are fairly well captured by the GCM. The RCM winds appear quite tightly constrained by the GCM, with no visible orographic channeling at this level (maximum model elevations are about $1000 \mathrm{~m}$ ).

The climatological mean monsoon onset dates are plotted in Fig. 3, computed using the local precipitation 
(a) r(GCM - MOS)

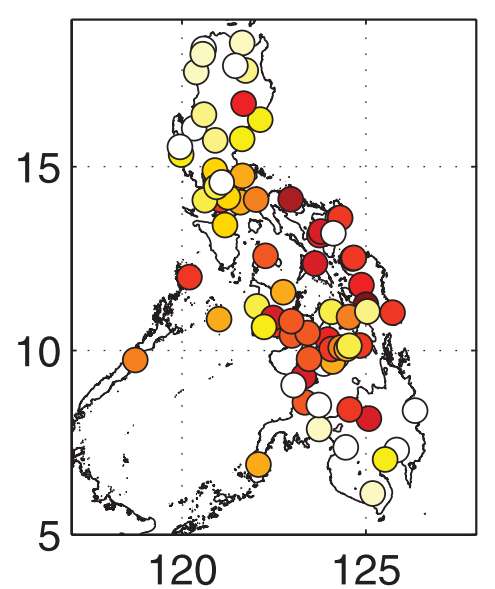

(b) $r(R C M-M O S)$

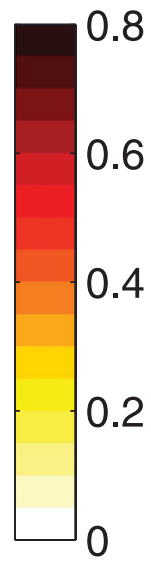

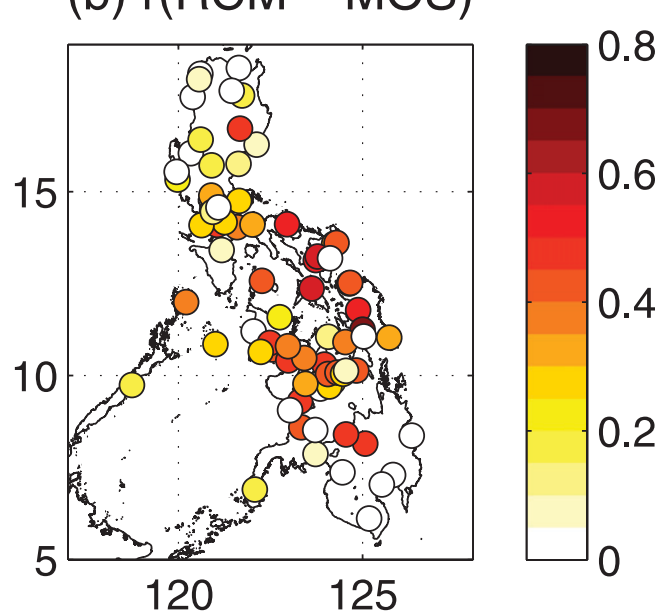

(c) Correlation values

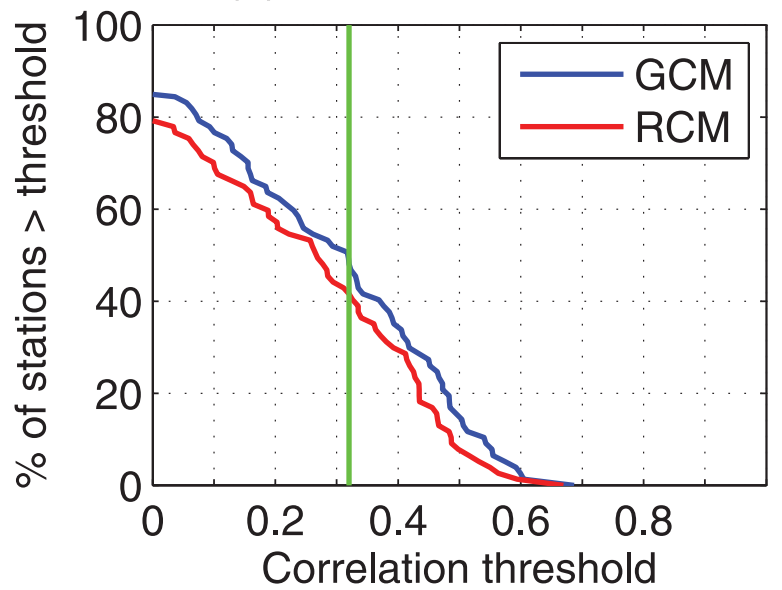

FIG. 7. ACC between AMJ seasonal-average PAGASA rainfall data and MOS-corrected simulations of (a) GCMand (b) RCM-simulated precipitation. (c) The percentage of stations exceeding a given correlation value, with the $95 \%$ one-tailed statistical significance value indicated as vertical line. Only positive values are plotted.

criteria as described in section 2e. Observed onset dates (Fig. 3a) range from late April along the east coast and over Mindanao, where the summer monsoon is less pronounced (cf. Moron et al. 2009), to late May/early June along the west coast. The GCM (Fig. 3b) is clearly too coarse to capture the rainfall onset with regional specificity, while capturing a northward extension of the onsets in April/May over Philippines longitudes, despite the lack of land points in the GCM. Although the RCM resolves much more detail, its mean onset dates are generally premature over much of the central and northern areas, perhaps due to the general overestimation of rainfall over the topography. At the station locations, the RCM's onsets are about 8 days earlier than those of the PAGASA data in the mean. Only over the western coast of Luzon are the later mean onsets associated with the southwest monsoon well captured.

Histograms of April-June daily precipitation values are plotted in Fig. 4 pooled over the 77 PAGASA station locations and nearest-neighbor RCM grid points; the GCM distribution is shown for the single GCM Philippines land point. In each case, a single model ensemble member was used. The GCM's distribution is highly truncated, with no values greater than $61 \mathrm{~mm}$, whereas that of the RCM has the opposite problem, tending to have unrealistically heavy rainfall events. The shape of the RCM's distribution is notably less exponential than that of the PAGASA data, resembling an inverse power law, and exhibits too few dry days $\left(<1 \mathrm{~mm} \mathrm{day}^{-1}\right)$. 
(a) RPSS(GCM - MOS)

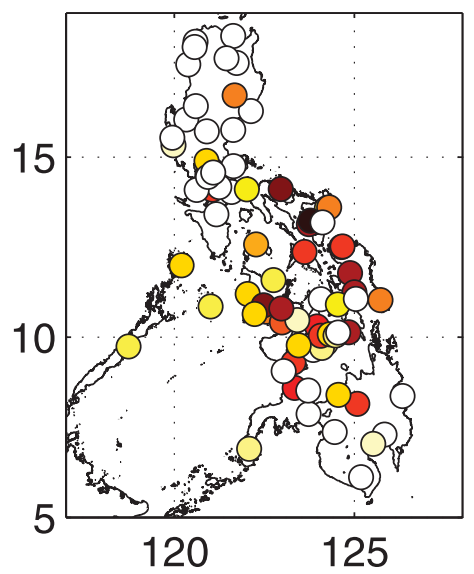

(b) RPSS(RCM - MOS)

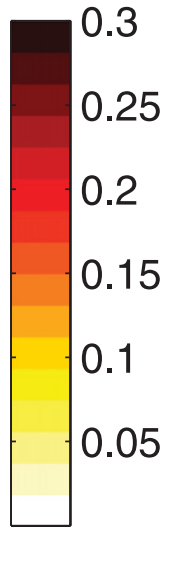

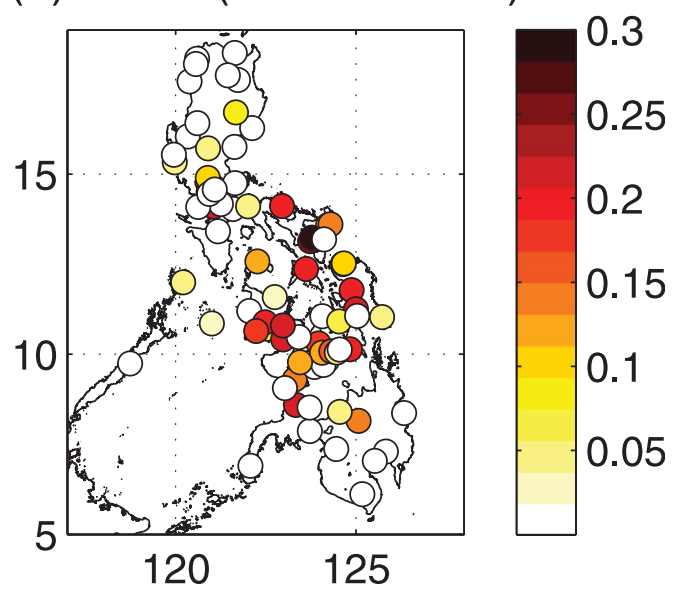

(c) RPSS values

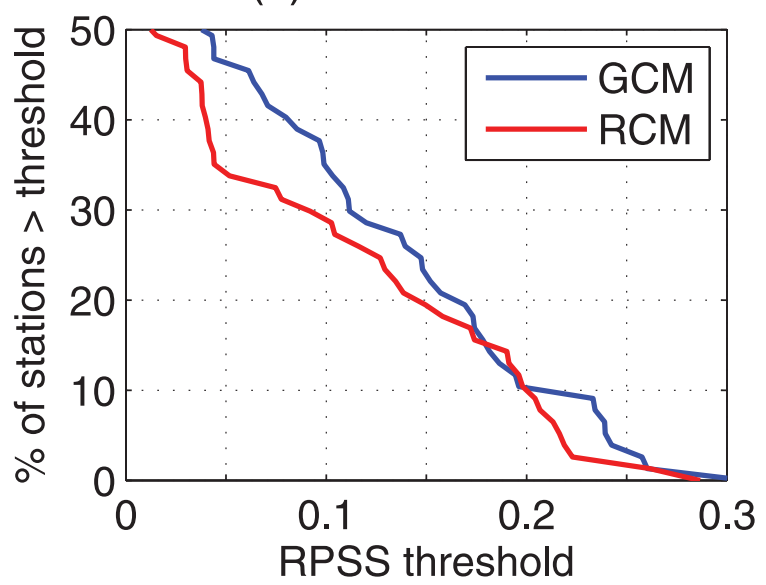

FIG. 8. RPSS for simulations of AMJ seasonal-average rainfall interpolated to station locations: (a) GCM, (b) RCM, and (c) histograms of RPSS values. Only positive RPSS values are plotted.

\section{b. Interannual variability}

\section{1) SPATIALly interpolated AMJ PRECIPITATION}

The anomaly correlation coefficient (ACC) skill of the ensemble-mean model simulations of April-June precipitation amount is shown in Fig. 5 interpolated bilinearly to the PAGASA station locations. Use of the RCM's nearest-neighbor grid point gave almost indistinguishable results. The figure shows maps of ACC values, together with the percentage of stations that exceed a given ACC value. Prior to calculating the ACC, a leave-one-out "cross-validation" was used to standardize the model and observation datasets, so as to mimic the real-time forecasting situation where one would not have the benefit of the observation in the current year when calculating anomalies. Thus, for each year the mean and standard deviation are computed for all the other years, and these values are then used to standardize the left-out year. This cross-validation step leads to small decreases in ACC values. A positive ACC of 0.32 corresponds to the $95 \%$ significance level according to a one-sided Student's $t$ test with $N-2=26$ degrees of freedom, which is indicated by a green line in Fig. $5 \mathrm{c}$.

Figure 5 can be interpreted as a comparison between very crude statistical downscaling (i.e., interpolation from GCM grid points; Fig. 5a) versus dynamical downscaling in Fig. 5b. By this measure, the performance of the RCM is slightly better than that of the GCM, with 13 stations with correlations exceeding 0.4 , compared to just 5 for the GCM; however, even in the RCM case, the locations with higher correlations are scattered throughout the Philippines. The correlation values are not obviously dependent on elevation, and the variability of precipitation 


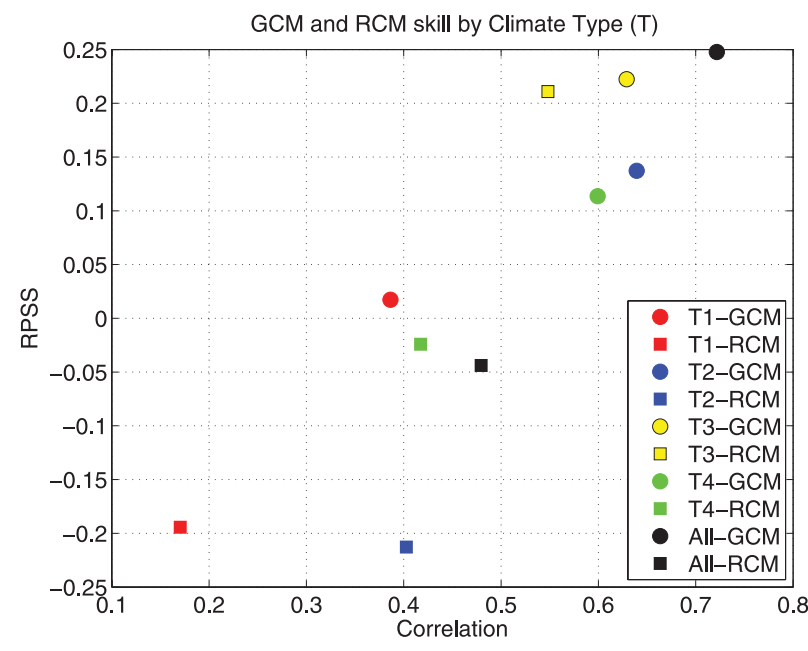

FIG. 9. Anomaly correlation and RPSS averaged over stations (SAI) in each climate type, for station-interpolated RCM (squares) and MOS-corrected GCM (circles) simulations.

is likely to depend on complex interactions between large-scale factors such as the monsoon circulation, ENSO, and local factors including elevation.

For a measure of probabilistic forecast skill, the ranked probability skill score (RPSS) (Epstein 1969), is shown in Fig. 6 in a similar format to Fig. 5, computed using the cross-validation procedure described in the previous paragraph. The RPSS is a squared error metric that measures the distance between the cumulative distribution functions of the GCM-/RCM-interpolated simulations and the verifying observations and is expressed with respect to a baseline given by the climatological distribution. A perfect simulation result would be represented by an RPSS of 1, whereas negative values indicate that the simulation for a particular year is less skillful than the climatological equal-odds guess. The RPSS was calculated here using tercile categories, as is typical in seasonal forecasting practice. These probabilities are estimated assuming a normal form for the distribution (except in Fig. 9), with mean given by the GCM or RCM ensemble mean and spread estimated by the standard deviation of the ensemble-mean simulation error residuals. This parametric method for estimating the distribution of the simulations was found to yield higher RPSS values than a simple counting of the ensemble members falling into each tercile category (Tippett et al. 2007) and to give slightly more reliable results compared to the method of Kharin and Zwiers (2003). (An example of the RPSS derived using counting is shown in Fig. 9.)

The RPSS station values of the interpolated GCM and RCM simulations in Fig. 6 are mostly negative-less than $30 \%$ are positive-indicating that the spatially interpolated simulations generally perform worse than climatology (i.e., issuing 33\% probabilities for each category); the RCM scarcely performs better than the GCM. Although RPSS values can be less easy to interpret than ACC in Fig. 5, it can be shown that, in the idealized case of well-calibrated normally distributed simulations, RPSS $\sim 1-\sqrt{1-r^{2}}$, in which case an ACC value of 0.4 equates to an RPSS of 0.083 .

\section{2) MOS OF AMJ PRECIPITATION FIELDS}

Here we apply leave-one-out cross-validated CCA to statistically downscale both the GCM and RCM simulations. The seasonally averaged $850-\mathrm{hPa}$ winds $(\sigma=0.85$ in the $\mathrm{RCM}$ ) were used as predictors of seasonal rainfall total at the 77 station locations, selecting all model grid points of the zonal and meridional wind components within the domains $\left(0^{\circ}-30^{\circ} \mathrm{N}, 110^{\circ}-140^{\circ} \mathrm{E}\right)$ and $\left(4^{\circ}-20^{\circ} \mathrm{N}\right.$, $117^{\circ}-129^{\circ} \mathrm{E}$ ) for the GCM and RCM, respectively. The latter domain corresponds approximately to the entire RCM domain, whereas the GCM domain was taken to be larger to reflect the large-scale nature of the ENSO teleconnection. Note that even with this larger domain there are only $110 \mathrm{GCM}$ grid points, as compared to the 3869 RCM ones. In each case the set of PCs accounting for $90 \%$ of the variance was retained in the CCA, for both predictor (i.e., winds) and predictand (i.e., 77 PAGASA station rainfall field). Use of the GCM or RCM precipitation fields in place of the low-level winds was found to degrade the results.

The resulting ACC scores are shown in Figs. 7 and 8. The ACC values show a marked improvement over those of the "raw" spatially interpolated simulations for both the GCM and the RCM, with 27 and 23 values exceeding 0.4 , respectively; the distributions of correlations are quite similar, with no advantage seen in the RCM. The improvements through MOS are largest over the central Philippines, whereas Luzon and Mindanao see decreased ACC values, especially in the RCM. The MOS RPSS values are greatly improved over the raw interpolated simulations, again especially over the central Philippines. Use of the RCM's near-surface wind field ( $\sigma$ $=0.995$ ) in place of the $\sigma=0.85$ level was found to degrade the MOS results.

\section{3) Summaries by ClimAte type}

Interstation differences are clear in the above figures of skill, but it is less obvious whether these are systematic or simply due to noise inherent in the small sample sizes analyzed. An additional intercomparison of methods is presented in Fig. 9, which shows the skill of the spatially interpolated RCM simulations (dynamical downscaling) versus MOS-corrected GCM simulations (statistical downscaling), averaged according to each of the four climate types in Fig. 1a using a standardized anomaly index 
(a) r(GCM,OBSfrq - MOS)

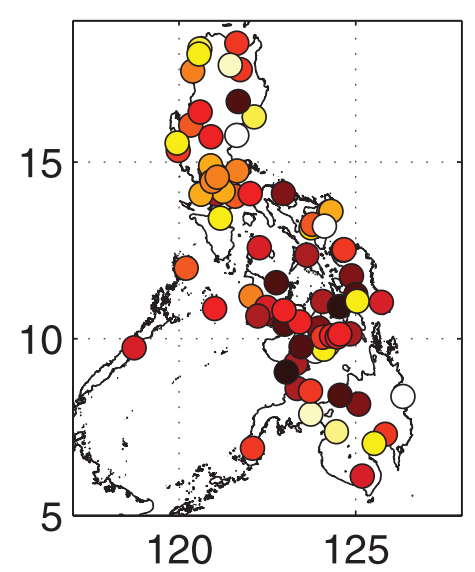

(b) $r($ RCM,OBSfrq - MOS)

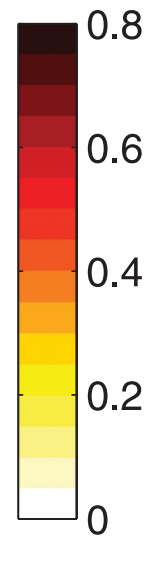

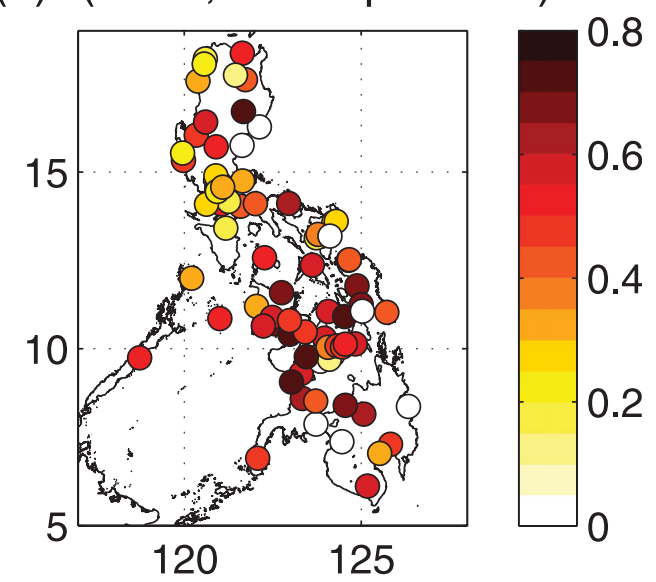

\section{(c) Correlation values}

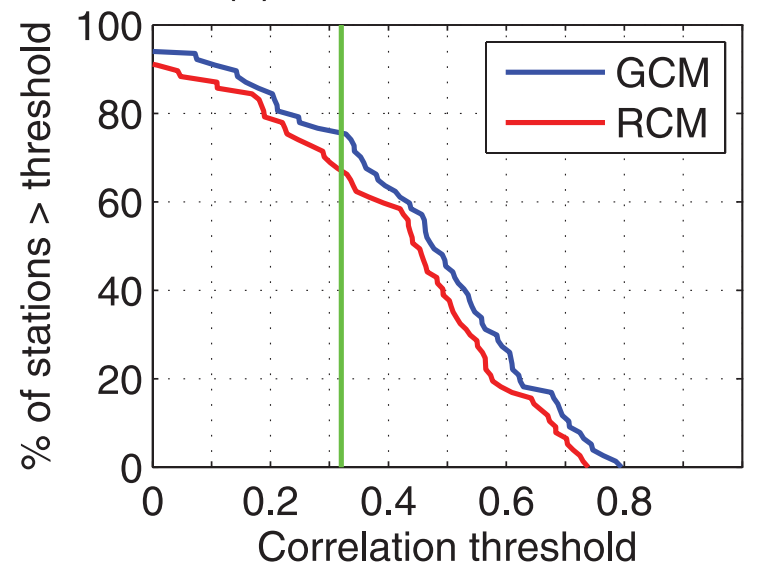

FIG. 10. ACC between AMJ seasonal-average PAGASA rainfall frequency and MOS-corrected simulations of (a) GCM- and (b) RCM-simulated winds. (c) The percentage of stations exceeding a given correlation value, with the $95 \%$ one-tailed statistical significance value indicated as vertical line. Only positive values are plotted.

(SAI; Katz and Glantz 1986). Here the RPSS is computed parametrically as in section $3 \mathrm{~b}(1)$ for the GCM, whereas, for the RCM, the counting method is used: that is, simply counting the number of RCM ensemble members (out of 10) that fall into each tercile category (cf. Robertson et al. 2004). A fairly linear relationship between ACC and RPSS is evident in Fig. 9, whereas GCM MOS skills always exceed those of the raw RCM. Climate type III is well forecasted by both methods, whereas types II and IV are only captured by the GCM MOS; the skill for type I is poor in both methods. Taking the entire Philippines (black symbols), the GCM MOS greatly outperforms the raw RCM, consistent with Figs. 5-8. It is notable that the RCM RPSS values are all negative (i.e., worse than climatology), except for type III, whereas they are always positive for the GCM. This difference may be attributed to the method used to calculate the RPSS, with the counting method based on the small 10-member RCM ensemble yielding very poor results, essentially because of sampling variability.

\section{4) DAILY PRECIPITATION FREQUENCY}

Previous studies have shown that in many tropical regions, seasonal anomalies of wet-day frequency are more spatially coherent than those of seasonal rainfall total, leading to higher seasonal predictability of the former at local scale (Moron et al. 2006, 2007, 2008). Figure 10 shows the ACC skill of the MOS method applied to the GCM and RCM, using the low-level seasonally averaged wind anomalies as predictors, as before, together with the observed rainfall frequency as the predictand. The skill in both cases is clearly higher than that of seasonal amount shown in Fig. 7, with fairly similar results in the GCM and RCM. The higher skill for rainfall frequency is 


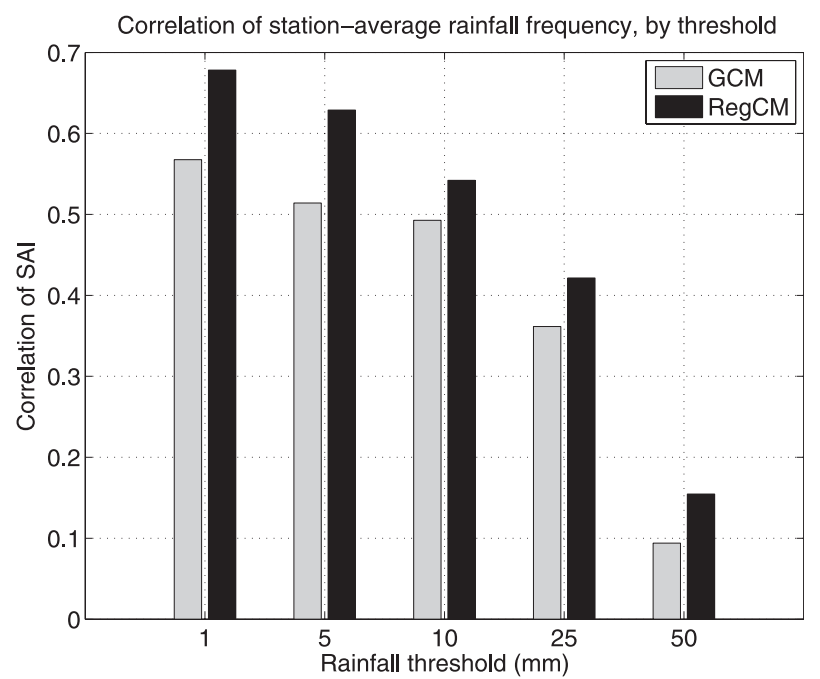

FIG. 11. ACC of AMJ station-averaged (SAI) rainfall frequency interpolated to station locations, as a function of rainfall threshold.

consistent with the less-noisy nature of this predictand, whereas the use of a seasonal-average winds as the predictor (as opposed to a GCM daily statistic) is chosen in keeping with the higher expected level of predictive information therein.

The role of the threshold used to define wet days is illustrated in Fig. 11 in terms of the all-Philippines SAI of model-simulated precipitation frequency, interpolated to the PAGASA stations. Note that Fig. 11 shows the raw interpolated ACC skill from the GCM and RCM daily rainfall simulations themselves, without the use of MOS. The skill is seen to decrease as the threshold increases, consistent with the greater noisiness of large precipitation intensities (Moron et al. 2007); the RCM always slightly outperforms the GCM, though the difference becomes small for high daily amount thresholds.

\section{5) Monsoon OnSET dATE}

For the case of monsoon onset date, the simulated daily evolutions in the GCM and RCM daily precipitation fields were found to yield poor skill when simply interpolated to the station locations. However, as in the case of the seasonal rainfall total and rainfall frequency, a CCA MOS using the AMJ-averaged zonal and meridional components of the low-level wind was found to yield promising anomaly correlation skill, especially over the central Philippines (Fig. 12); again, the RCM was not found to improve the skill of the GCM.

\section{6) Role of RECORD LENGTH}

Statistical downscaling via MOS requires training data for which both model simulations and historical data are available, in addition to independent data for forecast verification. To assess the role of record length, the 28-yr set of observations and simulations was divided into two equal halves. The CCA MOS was then carried out using leave-one-year-out cross-validation for each 14-yr set and the anomaly correlation skills obtained from each half averaged together. The median ACCs obtained are $(r=0.06,0.01)$ for the GCM and RCM, respectively, as compared to $(r=0.32,0.29)$ for the full 28 -yr dataset. Thus, the MOS skill decreases to near zero in both cases. When the same procedure is repeated for the correlations of spatially interpolated simulations shown in Fig. 5, the scores are much more robust: the medians calculated over the full 28-yr period $(r=0.24,0.23)$ become $(r=0.25$, 0.21 ) when computed for each half separately and then averaged. This demonstrates the sensitivity of MOS to the length of the training set.

\section{Conclusions \\ a. Summary}

This study has compared the performance of dynamical downscaling of ECHAM4.5 T42 seasonal climate simulations with the RegCM3 nested model at $25-\mathrm{km}$ resolution over the Philippines, against statistical downscaling using leave-one-out cross-validated canonical correlation analysis. Models are built and tested using a 77 -station daily precipitation dataset over the 28 -yr period of 1977-2004, for the AMJ monsoon onset season. The statistical downscaling is compared against the GCM and $\mathrm{RegCM} 3$ gridpoint values linearly interpolated to the station locations. Besides AMJ-average precipitation, daily rainfall frequency and the onset date of the summer monsoon are also considered. Skill is quantified using anomaly correlation and RPSS.

The anomaly correlation coefficient (ACC) skill at the station scale for simulations of seasonal total rainfall is generally somewhat higher in the RCM compared to the GCM when using spatial interpolation (Fig. 5). However, the ACC skill obtained using MOS of the GCM wind field is shown to be generally superior (Fig. 7); the ranked probability skill score (RPSS) is also much higher when using MOS, especially over the central Philippines (Figs. 6,8 ). The application of MOS to the RCM output yielded similar results to that of the GCM. Very high skills were found for MOS correction of seasonal-average daily rainfall frequency as a function of seasonal-average lowlevel wind fields, but with no apparent advantage from the RCM (Fig. 10); MOS-corrected monsoon onset dates often showed skill values similar to those of seasonal rainfall total, with good skill over the central Philippines (Fig. 12). Finally, it is shown that the MOS skills decrease markedly and become inferior to those of 
(a) r(GCM,OBSonset - MOS)

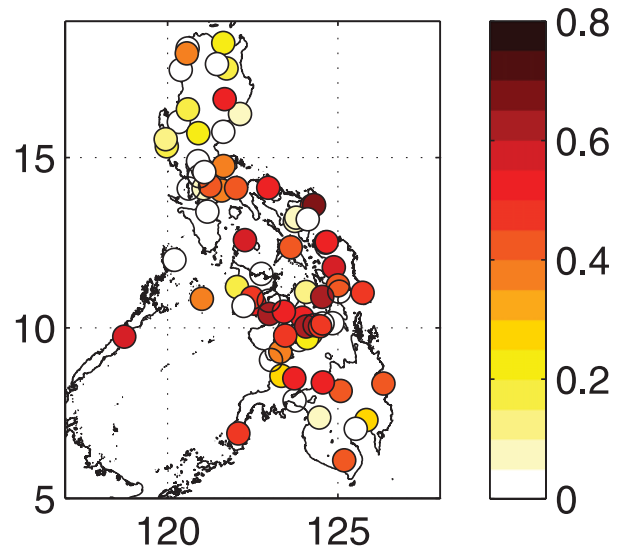

(b) $r(\mathrm{RCM}, \mathrm{OBS}$ onset - MOS)

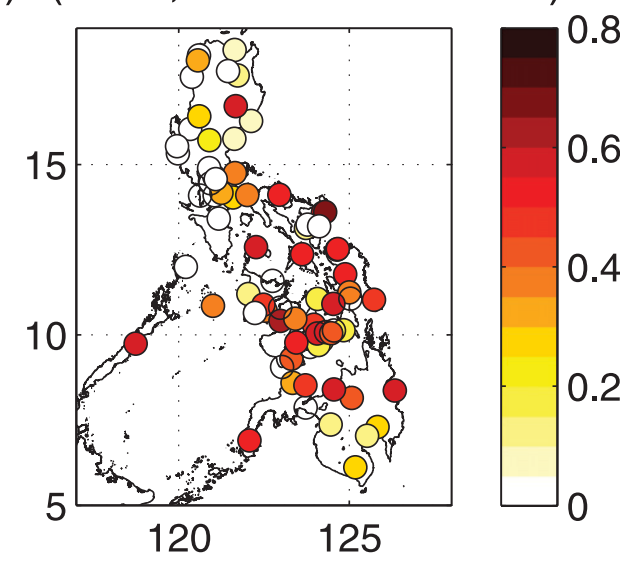

(c) Correlation values

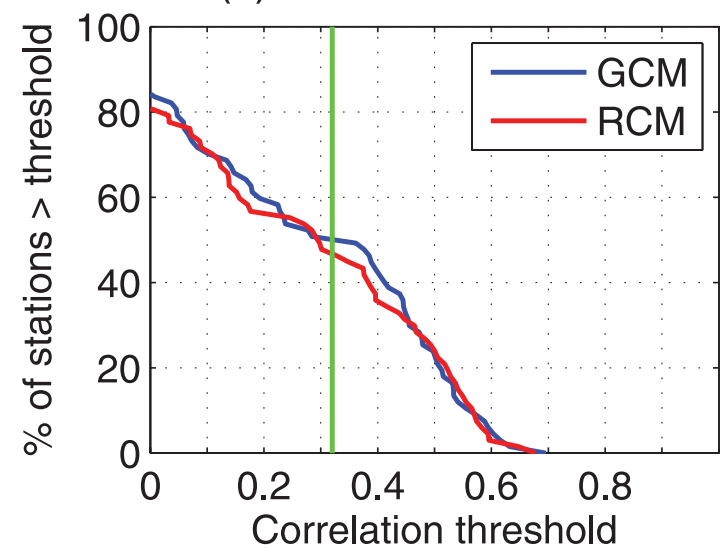

FIG. 12. ACC between observed station monsoon onset dates and MOS-corrected simulation from (a) GCM- and (b) RCM-simulated winds. (c) The percentage of stations exceeding a given correlation value, with the $95 \%$ onetailed statistical significance value indicated as vertical line. Only positive values are plotted.

spatial interpolation when the length of the training set is halved (Fig. 13).

\section{b. Discussion}

The results presented here demonstrate that there is generally little advantage to the use of the RCM for downscaling of seasonal GCM simulations of precipitation to station locations over the Philippines, because the seasonal anomalies associated with ENSO are strong and the data records are sufficiently long to enable successful MOS correction. There are three main caveats that should be borne in mind when interpreting this finding. First, it may be region specific; the Philippines has good station records and is strongly impacted by ENSO, allowing regression models to be built effectively. Second, attention has been restricted to station locations; if results are required on a high-resolution grid, such as to drive a distributed hydrologic catchment model, then the case for dynamical downscaling would be more compelling. Third, the conclusions are likely only to be valid on interannual time scales where MOS can be used effectively to match simulations or retrospective seasonal forecasts to a set of historical observations. Although the intercomparison was carried out in the simulation context, we can expect that similar conclusions would be reached in a two-tier retrospective seasonal forecast setting with the sole difference being the use of predicted SSTs and a concomitant decrease in skill levels overall. This approach cannot generally be taken for climate change projections, where a "perfect prognosis" method must be used in which regression models are derived using reanalysis data, and then the regression model is assumed to be applicable to the GCM, as well as to hold under future climates. Because nonstationarity is a fundamental characteristic of climate change, a physically based RCM becomes much more attractive. 
(a) r(GCM - MOS 2 halves)

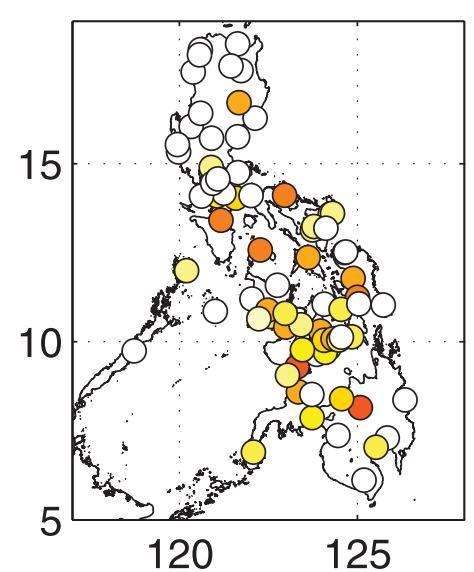

(b) $r(\mathrm{RCM}-\mathrm{MOS} 2$ halves)

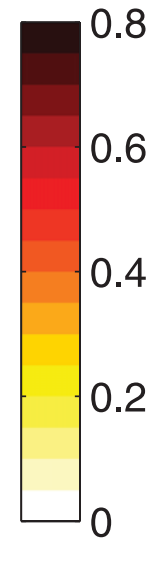

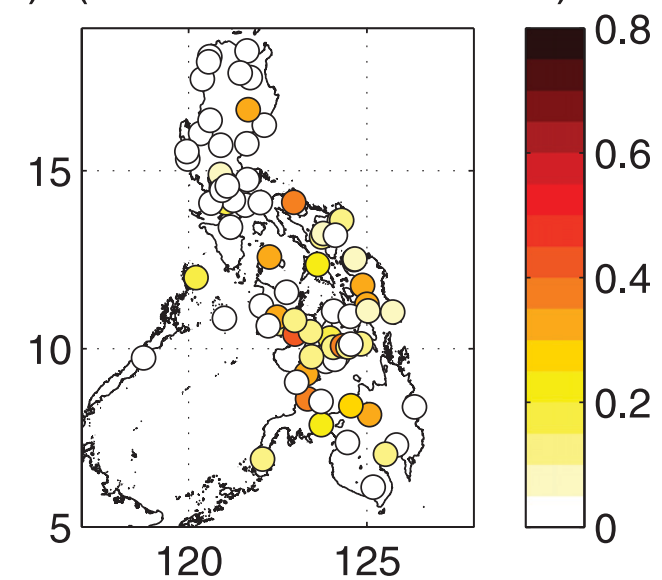

(c) Correlation values

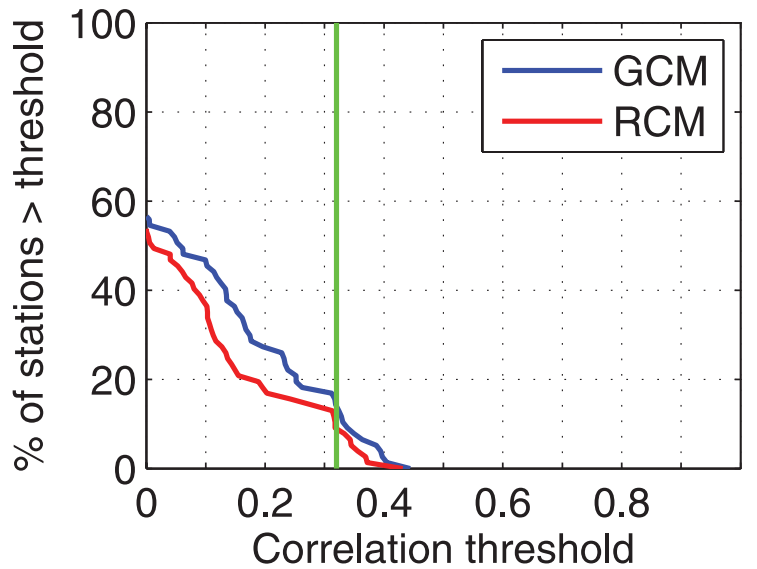

FIG. 13. As in Fig. 7, but for the MOS performed on the 28-yr dataset split into two halves, with the corresponding two correlation values averaged together.

In the seasonal prediction context, given the skill of MOS techniques based on GCM wind fields, one might ask whether a GCM is needed at all and if similar skills could be obtained using antecedent SSTs, for example. Indeed, Moron et al. (2009) found fairly comparable skills for monsoon onset date over the Philippines when using March SSTs in place of GCM-simulated fields.

Additional caveats of our RCM implementation are the small domain and relatively coarse resolution used. The RCM winds are largely a function of the driving GCM winds, especially in a monsoon region such as the Philippines; in addition, this large-scale wind venting effect is stronger for smaller RCM domains. The underrepresentation of small islands and topography, especially in the central Philippines, with the $25-\mathrm{km}$ resolution used here will affect the RCM-simulated rainfall. Thus, a larger spatial domain at even higher resolution is likely to be needed for adequate dynamical downscaling of rainfall over the Philippines. A larger domain might also improve the representation of local rainfall associated with regional synoptic systems, such as tropical cyclones. Of course, a larger domain and high resolution would make operational climate forecasting much more computationally expensive. The lack of air-sea coupling and imperfect model physics are also potential candidates for the limitations of the RCM downscaling. In spite of such limitations, the RegCM3 has been shown using a similar resolution and configuration over Indonesia to produce quite realistic simulation of ENSO anomalies during the monsoon season, which contrast in polarity between highlands and lowlands because of differential ENSO impacts on the land-sea breeze (Qian et al. 2010).

A drawback of dynamical downscaling for seasonal forecasting is that multi-GCM ensembles have been found to generally outperform individual GCMs (e.g., Robertson et al. 2004). Thus multimodel ensembles are needed, but 
it is generally impractical to store all the needed 6-hourly GCM fields, and to downscale several GCMs dynamically, perhaps with multiple RCMs. Although some limited attempts at such multimodel dynamical downscaling have been made, statistical-dynamical "anomaly nesting" approaches may be fruitful, such as in Patricola and Cook (2010), who have used monthly-mean lateral boundary fields, or Beaulant et al. (2011), who have used a very-highresolution nonhydrostatic RCM to downscale daily weather types, with the latter downscaled statistically.

Acknowledgments. It is a pleasure to thank Brad Lyon, Simon Mason, and Liqiang Sun for useful discussions. The rainfall station data was kindly made available by the Philippine Atmospheric Geophysical and Astronomical Services Administration (PAGASA). The GCM model outputs from the International Research Institute for Climate and Society (IRI) were made possible by David Dewitt and through a computing grant from the multiagency Climate Simulation Laboratory (CSL) program. This work was supported by NOAA through a block grant to IRI.

\section{REFERENCES}

Beaulant, A.-L., and Coauthors, 2011: Statistico-dynamical downscaling for Mediterranean heavy precipitation. Quart. J. Roy. Meteor. Soc., 137, 736-748, doi:10.1002/qj.796.

Coronas, J., 1920: The Climate and Weather of the Philippines, 1903-1918. Manila Bureau of Printing, 195 pp.

Emanuel, K. A., and M. Zivkovic-Rothman, 1999: Development and evaluation of a convective scheme for use in climate models. J. Atmos. Sci., 56, 1766-1782.

Epstein, E. S., 1969: A scoring system for probability forecasts of ranked categories. J. Appl. Meteor., 8, 985-987.

Fowler, H. J., S. Blenkinsop, and C. Tebaldi, 2007: Linking climate change modelling to impacts studies: Recent advances in downscaling techniques for hydrological modelling. Int. J. Climatol., 27, 1547-1578.

Goddard, L., A. G. Barnston, and S. J. Mason, 2003: Evaluation of the IRI's "net assessment" seasonal climate forecasts: 1997 2001. Bull. Amer. Meteor. Soc., 84, 1761-1781.

Hansen, J. W., A. Challinor, A. Ines, T. Wheeler, and V. Moron, 2006: Translating climate forecasts into agricultural terms: Advances and challenges. Climate Res., 33, 27-41.

Joyce, R. J., J. E. Janowiak, P. A. Arkin, and P. Xie, 2004: CMORPH: A method that produces global precipitation estimates from passive microwave and infrared data at high spatial and temporal resolution. J. Hydrometeor., 5, 487-503.

Kalnay, E., and Coauthors, 1996: The NCEP/NCAR 40-Year Reanalysis Project. Bull. Amer. Meteor. Soc., 77, 437-471.

Katz, R. W., and M. H. Glantz, 1986: Anatomy of a rainfall index. Mon. Wea. Rev., 114, 764-771.

Kharin, V. V., and F. W. Zwiers, 2003: Improved seasonal probability forecasts. J. Climate, 16, 1684-1701.

Lyon, B., H. Cristi, E. R. Verceles, F. D. Hilario, and R. Abastillas, 2006: Seasonal reversal of the ENSO rainfall signal in the Philippines. Geophys. Res. Lett., 33, L24710, doi:10.1029/ 2006GL028182.
Moron, V., A. W. Robertson, and M. N. Ward, 2006: Seasonal predictability and spatial coherence of rainfall characteristics in the tropical setting of Senegal. Mon. Wea. Rev., 134, 3248-3262.

$-, \ldots, \ldots$, and P. Camberlin, 2007: Spatial coherence of tropical rainfall at the regional scale. J. Climate, 20, 5244-5263.

,,,--- and O. Ndiaye, 2008: Weather types and rainfall over Senegal. Part I: Observational analysis. J. Climate, 21, 266-287.

—, A. Lucero, F. Hilario, B. Lyon, A. W. Robertson, and D. DeWitt, 2009: Spatio-temporal variability and predictability of summer monsoon onset over the Philippines. Climate Dyn., 33, 1159-1177.

_ A. W. Robertson, and J.-H. Qian, 2010: Local versus regionalscale characteristics of monsoon onset and post-onset rainfall over Indonesia. Climate Dyn., 34, 281-299.

Pal, J. S., and Coauthors, 2007: Regional climate modeling for the developing world: The ICTP RegCM3 and RegCNET. Bull. Amer. Meteor. Soc., 88, 1395-1409.

Patricola, C., and K. Cook, 2010: Northern African climate at the end of the twenty-first century: An integrated application of regional and global climate models. Climate Dyn., 35, 193-212.

Qian, J.-H., 2008: Why precipitation is mostly concentrated over islands in the Maritime Continent. J. Atmos. Sci., 65,1428-1441.

— A. W. Robertson, and V. Moron, 2010: Interactions among ENSO, the monsoon, and diurnal cycle in rainfall variability over Java, Indonesia. J. Atmos. Sci., 67, 3509-3524.

Robertson, A. W., U. Lall, S. E. Zebiak, and L. Goddard, 2004: Improved combination of multiple atmospheric GCM ensembles for seasonal prediction. Mon. Wea. Rev., 132, 2732-2744.

_ V. Moron, and Y. Swarinoto, 2009: Seasonal predictability of daily rainfall statistics over Indramayu district, Indonesia. Int. J. Climatol., 29, 1449-1462.

Roeckner, E., and Coauthors, 1996: The atmospheric general circulation model ECHAM4: Model description and simulation of present-day climate. Max Planck Institute for Meteorology Tech. Rep. 218, 90 pp.

Sun, L., D. F. Moncunill, H. Li, A. D. Moura, and F. A. S. Filho, 2005: Climate downscaling over Nordeste, Brazil, using the NCEP RSM97. J. Climate, 18, 551-567.

- , H. Li, M. N. Ward, and D. F. Moncunill, 2007: Climate variability and corn yields in semiarid Ceará, Brazil. J. Appl. Meteor. Climatol., 46, 226-240.

Tippett, M. K., M. Barlow, and B. Lyon, 2003: Statistical correction of central Southwest Asia winter precipitation simulations. Int. J. Climatol., 23, 1421-1433.

— A. G. Barnston, and A. W. Robertson, 2007: Estimation of seasonal precipitation tercile-based categorical probabilities from ensembles. J. Climate, 20, 2210-2228.

Verbist, K., A. W. Robertson, W. M. Cornelis, and D. Gabriels, 2010: Seasonal predictability of daily rainfall characteristics in central northern Chile for dry-land management. J. Appl. Meteor. Climatol., 49, 1938-1955.

Widmann, M., C. S. Bretherton, and E. P. Salathé, 2003: Statistical precipitation downscaling over the northwestern United States using numerically simulated precipitation as a predictor. J. Climate, 16, 799-816.

Wilby, R. L., T. M. L. Wigley, D. Conway, P. D. Jones, B. C. Hewitson, J. Main, and D. S. Wilks, 1998: Statistical downscaling of general circulation model output: A comparison of methods. Water Resour. Res., 34, 2995-3008.

Wilks, D. S., and R. L. Wilby, 1999: The weather generation game: A review of stochastic weather models. Prog. Phys. Geogr., 23, 329-357. 